\title{
Garantías procesales en la aplicación de la inteligencia artificial y el Big Data en el estándar de la prueba penal
}

\author{
Procedural guarantees in the application of Al and Big Data in the \\ standard of criminal evidence \\ Jeison Estiven Pineda Nobles ${ }^{1}$
}

Fecha correspondencia:

Recibido: 15 de julio de 2020.

Revisión: 26 de enero de 2021

Aceptado: 5 de febrero de 2021

\section{Forma de citar:}

Pineda, Jeisson Stiven. (2021)

"Garantías procesales en la

aplicación de la inteligencia

artificial y el big data en el estánda

de la prueba penal" En: Revista CES

Derecho. Vol. 12, №. 1, enero a junio de 2021, p. 108-125.

Open access

Términos de uso

Licencia creative commons

Etica de publicaciones

Revisión por pares

Gestión por Open Journal System

DOl: http://dx.doi.org/10.21615/

cesder.12.1.6

ISSN: 2145-7719

Sobre los autores:

1. Abogado Corporación

Universitaria de Colombia IDEAS.

\section{Resumen}

El siguiente texto tiene como finalidad establecer cómo los avances científicos y tecnológicos que posee el fenómeno de la cuarta revolución industrial de pueden constituir mejoras en las garantías procesales penales dentro del estándar de más allá de toda duda razonable, a través de la inclusión de la Inteligencia Artificial y el Big Data en el marco del derecho probatorio en relación con elementos como: la prueba, la valorización de la prueba, la sana crítica y los medios probatorios.

Palabras claves: Cuarta Revolución Industrial, más allá de la duda razonable; Big Data, Inteligencia Artificial, medios probatorios.

\section{Abstract}

The purpose of the following text is to establish how the scientific and technological advances that the phenomenon of the fourth industrial revolution possesses can constitute improvements in criminal procedural guarantees within the standard beyond all reasonable doubt, through the inclusion of Intelligence. Artificial and Big Data within the framework of evidentiary law in relation to elements such as: evidence, assessment of evidence, sound criticism and evidence.

Keywords: Fourth Industrial Revolution, beyond reasonable doubt; Big Data, Artificial Intelligence, evidence.

\section{Introducción}

La Constitución Política de 1991 es un claro ejemplo de un modelo garantista, el cual se adecua armónicamente al modelo expuesto por (Ferrajoli, 1995) en "Derecho y Razón", toda vez que esta ajusta a las tres acepciones del garantismo de Ferrajoli, a saber: (a) el modelo de estricta legalidad como sistema cognoscitivo de poder mínimo; (b) técnica de tutela en el plano político, con el cual se minimiza la violencia y amplia la libertad; y (c), sistema de vínculos impuestos a la potestad punitiva del estado en garantía de los derechos de los ciudadanos en el plano jurídico. Estos tres elementos que definen el modelo garantista son visto en el marco constitucional en los Derechos Fundamentales reconocidos en ella, los mecanismos 
de defensa o amparo de estos mismos y la estructura organizacional-funcional del estado en pro del bienestar social. Conjuntamente, si la finalidad del garantismo de Ferrajoli está en la protección de los Derechos Fundamentales, este marco es completamente adherido en la Carta Política de 1991.

Una subrama de la Teoría Garantista se encuentra en la defensa de principios y derechos procesales del ciudadano, inscritos en el marco constitucional y convencional colombiano, que entienden el debido proceso y la defensa técnica, guiadas desde un juicio objetivo y bajo la lupa de un juez natural. Estas garantías procesales, en materia penal, entienden estándares probatorios como inferencia razonable, probabilidad de verdad y conocimiento más allá de toda duda razonable, lo que permite una orientación al aparato judicial en la toma de decisiones disminuyendo las afectaciones a los derechos fundamentales del debido proceso y defensa técnica.

Sin embargo, estas premisas consideradas, se han visto afectadas con los avances tecnológicos, especialmente con la "cuarta revolución industrial" que, además de traer consigo nuevos escenarios de análisis para los jueces penales y civiles, conlleva a la necesidad de implementación de herramientas como los es la Inteligencia Artificial (IA) y sistemas masivos de Datos (Big Data) en aras de sostener el principio básico de la epistemología jurídica de la sociedad y el derecho unísonos en materia de regulaciones legales. Bajo estas consideraciones se debe analizar el impacto y la necesidad estricta de implementar al modelo procesal garantista estas herramientas que trae consigo la cuarta revolución industrial (IA y Big Data) en el marco de los estándares de la prueba penal como marco de referencia de análisis para los jueces penales; es así como se plantea el siguiente problema de investigación: ¿Puede el uso de la IA constituir una herramienta que conlleve a mejorar la aplicación de los estándares probatorios penales a fin de constituir garantías procesales al procesado?

Como método para resolver el anterior problema se utilizará el siguiente esquema, a través de la metodología exegética y analítica:

1. Definir las garantías procesales a fin de entender cuáles son las garantías del procesado.

2. Analizar los componentes de la Cuarta Revolución Industrial a fin de extraer las herramientas que sirviesen al derecho en materia probatoria.

3. Analizar el Big Data y la IA como herramientas de valoración probatoria y sus relaciones con los componentes probatorios en el proceso y la sana crítica.

\section{Garantías y derecho procesales}

El garantismo jurídico entiende dos principios fundamentales: el principio de legalidad y el principio de legitimidad; estos principios entienden el desarrollo de toda la teoría garantista de Ferrajoli. En primer lugar, la legalidad, entiende el plano formal y es la subordinación de los poderes públicos a las leyes generales y abstractas; el plano sustancial constituye la funcionalidad de estos poderes estatales al servicio de las garantías de los derechos fundamentales, incorporando los deberes públicos, siendo la prohibición de lesionar derechos y libertades (Ferrajoli, 1995, págs. 856-857); el marco jurídico del estado de Colombia, entiende estos apartados descritos por el jurista, en lo concerniente a la parte dogmática constitucional (arts. 11-45) como plano sustancial; y el plano formal bajo los principios constitucionales (arts.1-10), 
específicamente el artículo $4^{\circ}$ que dicta: "La constitución es norma de normas. En todo caso de incompatibilidad entre la constitución y la ley u otra norma jurídica, se aplicarán las disposiciones constitucionales". (Constitución Política, 1991).

Por otro lado, el principio de legitimidad, como indica Bobbio (1985) refiere a la titularidad del poder, un base de fundamento para el derecho a gobernar; bajo las perspectivas de este filosofo: "la legitimidad es el fundamento de su deber de obedecer; la legalidad es la garantía de su derecho de no ser oprimido" (p.30). Estos principios, que entienden la relación entre el pueblo soberano y los gobernantes, en la analogía súbdito-gobernante, entienden los derechos del pueblo a no ser oprimidos en consonancia con el deber de gobernar justamente (legalidad) a cambio del deber de obedecer la titularidad del poder del gobierno (legitimidad). Entendiendo así que los derechos de los ciudadanos son el deber del estado y los deberes de estos a su vez traducen el derecho legítimo de gobernar.

Conjuntamente a esto, como se observa, la base gravitacional del garantismo jurídico es el amparo de los derechos fundamentales, establecidos en la Constitución y, toda ley ordinaria o especial, debe estar en armonía con estos principios y derechos constitucionales, el desarrollo de las normas garantistas debe ir en esta línea. Por otro lado, los derechos fundamentales, sus respectivas clasificaciones en individuales y colectivos y del medio ambiente, entienden un desarrollo normativo conforme al principio de legalidad sustancial. A lo cual, se le suma los derechos y garantías procesales, como medios de protección o disminución de afectación, de los derechos descritos en la parte dogmática de la constitución. En relación a esto, el artículo $29^{\circ}$ de la Carta Política define el debido proceso de la siguiente forma:

Artículo $29^{\circ}$. El debido proceso se aplicará a toda clase de actuaciones judiciales y administrativas. [...] Nadie podrá ser juzgado sino conforme a leyes preexistentes al acto que se le imputa, ante juez o tribunal competente y con observancia de la plenitud de las formas propias de cada juicio. [...] En materia penal, la ley permisiva o favorable, aun cuando sea posterior, se aplicará de preferencia a la restrictiva o desfavorable. [...] Toda persona se presume inocente mientras no se la haya declarado judicialmente culpable. Quien sea sindicado tiene derecho a la defensa y a la asistencia de un abogado escogido por él, o de oficio, durante la investigación y el juzgamiento; a un debido proceso público sin dilaciones injustificadas; a presentar pruebas y a controvertir las que se alleguen en su contra; a impugnar la sentencia condenatoria, y a no ser juzgado dos veces por el mismo hecho. [...] Es nula, de pleno derecho, la prueba obtenida con violación del debido proceso. (Constitución Política, 1991).

La misma Corte Constitucional, en sentencia (C-341, 2014) desarrolla el concepto de debido proceso, definiendo dentro de este mismos las siguientes garantías (a) derecho a la jurisdicción, que entiende el acceso a la administración de justicia, la segunda instancia, el derecho de interponer recursos y obtener decisiones motivadas; (b) derecho al juez natural de acuerdo con la naturaleza fáctica; (c) derecho a la defensa, donde entiende el empleo de los medios legítimos y adecuados para ser escuchado y obtener una decisión favorable, donde se entiende la preparación de defensa en tiempo y material probatorio para controvertir, la defensa técnica y el acompañamiento de un profesional en Derecho, igualdad procesal e igualdad en armas; (d) audiencias publica desarrollada en tiempo razonable, sin dilaciones injustificada o inexplicables; (e) independencia del juez bajo la separación de poderes, 
orientado como único deber el de administrar justicia; y, (f) imparcialidad, para decidir con fundamento a los hechos y conforme a los imperativos jurídicos.

Las garantías procesales se dan a través de los medios probatorio, con la finalidad de llegar a una conclusión en un conflicto, bien sea que haga parte de la jurisdicción ordinario o extraordinaria. El debido proceso, como derecho fundamental, tiene una estrecha relación con las pruebas que se allegan a fin de defender los interés particulares o generales; entendiendo así que el marco axiológico del debido proceso entiende una relación estrecha con la prueba, siendo así que la prueba comprende la base gravitacional del proceso. Es así como, la prueba, persigue fines en la Fiscalía y ante el Juez, posee fundamentos como la carga probatoria, la libertad probatoria, y el debido proceso, además de su respectivo procedimiento.

Siguiendo con esta línea, relacionando las garantías procesales con la prueba, se debe entender que los medios probatorios en Colombia son amplios, según el artículo $165^{\circ}$ del código general del proceso (Ley 1564, 2012) dice que estos son: "la declaración de parte, la confesión, el juramento, el testimonio de terceros, el dictamen pericial, la inspección judicial, los documentos, los indicios, los informes y cualesquiera otros medios que sean útiles para la formación del convencimiento del juez". Dentro de estos medios útiles se debe considerar que la necesidad probatoria de la cual habla el artículo $164^{\circ}$ del mismo código, constituye que las decisiones judiciales se fundamentan en la credibilidad probatoria aportada dentro del juicio. Es menester entender, a priori, que la prueba, según indica (Taruffo, 2009):

[...] es el instrumento que utilizan las partes desde hace siglos para demostrar la veracidad de sus afirmaciones, y del cual se sirve el juez para decidir respecto a la verdad o falsedad de los enunciados fácticos. En términos muy generales, se entiende como prueba cualquier instrumento, método, persona, cosa o circunstancia que pueda proporcionar información útil para resolver dicha incertidumbre. Según esta definición, son prueba tanto los instrumentos para adquirir información que están expresamente regulados por la ley (las denominadas pruebas típicas) como aquellos que la ley no regula expresamente (las denominadas pruebas atípicas) pero que, sin embargo, pueden servir para fundar la decisión sobre los hechos. (pp. 59-60).

La importancia de la prueba está en el esclarecimiento del hecho, sencillamente devela el nexo causal existente entre la presunta falta y el responsable de la misma; además estas sitúan el camino de la decisión judicial; ahora bien, en una necesidad imperiosa, se recalca la estructura de (García Flores, 2002) sobre la prueba, la cual es:

1. Concepto;

2. Órgano y sujeto;

3. Finalidad o teleología;

4. Fuente;

5. Objeto;

6. Procedimiento;

7. Medios;

8. Carga;

9. Valoración. 
Cada uno de estos elementos está dirigido a responder a las cuestiones sobre ¿qué es la prueba? ¿qué se prueba? ¿quién prueba? ¿cómo se prueba? ¿cuál es el valor de la prueba? Debe entenderse que esta estructura propuesta por Flores García (2002) conlleva a una dirección en materia probatoria que es evaluada al final por el juez dentro de la audiencia; con respecto al concepto se relaciona con el verbo evidenciar o verificar, siendo esto por los sujetos procesales que se representan por las partes; en sí quienes buscan evidenciar o aclarecerle al juez la verdad mediante la prueba son las partes que se encuentran en litis, esto lo hacen con la finalidad de que sus pretensiones sean aceptadas por la imparcialidad del juez. La fuente de la prueba es el lugar de donde fue, es decir, se cobija en la forma en la que fue tomada en primer orden, señalando conforme al mismo artículo 29 constitucional y $23^{\circ}$ en la normatividad procesal penal, esclareciendo que toda prueba obtenida con violación del debido proceso es nula de pleno derecho. Conjuntamente todo esto apunta al objeto de la prueba que es sostener las pretensiones previamente señaladas al juez; para esto la misma prueba posee un control, para establecer si posee una relación directa o indirecta con los hechos señalados; si existe una idoneidad que enmarca su presentación y si es de utilidad dentro del proceso, es decir, que no sea repetitiva. Esto se hace a través de los medios previamente señalados y la carga de probar el hecho ocurrido esta sobre el ente acusador, en materia penal. Estos puntos, al estar en la valorización del juez, tienen una estrecha relación con los criterios de la "sana crítica" en la cual el juez debe exponer las razones por las cuales establece la decisión sobre las mismas.

Siguiendo estos puntos, la sana crítica aparece como otro elemento que se relaciona con el debido proceso y sus garantías procesales, esta, en palabras de (Barrios, 2003), es "el arte de juzgar, atendiendo a la bondad y verdad de los hechos, sin vicios ni error, mediante la lógica, la dialéctica, la experiencia, la equidad y las ciencias y artes afines y auxiliares y la moral, para alcanzar y establecer, con expresión motivada, la certeza sobre la prueba que se produce en el proceso" (p. 102). También es necesario agregar a estos componentes el valor del precedente judicial, toda vez que los jueces tienen la estricta obligación de continuar con su línea y, sólo bajo argumentos válidos y esclareciendo sus razones, pueden alejarse del mismos.

Estos criterios, aplicados hasta la actualidad, comprenden el escenario que ha ido desarrollándose y aplicándose para mantener las garantías del procesado. Entendiendo la existencia de los estándares de la prueba que orientan y limitan el desarrollo del juicio, los cuales tienen una íntima relación con la sana crítica: estos constituyen la base de apoyo de la sana crítica. Dado que la investigación está orientada al proceso penal, sólo se toman los estándares probatorios en esta área, pero cabe aclarar que los estándares generales son "más allá de toda duda razonable" en materia penal y "probabilidad de verdad" en el área civil. Es menester analizar ahora la relación entre los estándares de prueba penal y las garantías procesales vistas con anterioridad; esto a fin de conllevar una conexión con los principios procesales penales que amparan las garantías procesales vistas.

Lo visto preliminarmente entiende una relación entre la prueba, el debido proceso penal, las garantías procesales que también se observan en el marco normativo-penal, en la (Ley 906, 2004), en los principios de imparcialidad (art. $5^{\circ}$ ), legalidad (art. 6º), presunción de inocencia $\left(\operatorname{art} .7^{\circ}\right)$, defensa $\left(\operatorname{art} .8^{\circ}\right)$, actuación procesal $\left(\operatorname{art} .10^{\circ}\right)$, contradicción (art. $15^{\circ}$ ), inmediación (art. 16\%), concentración (art. 17\%), publicidad (art. $18^{\circ}$ ), juez natural (art. $19^{\circ}$ ), doble instancia (art. $20^{\circ}$ ), cosa juzgada (art. $21^{\circ}$ ) y la cláusula de exclusión (art. $23^{\circ}$ ). Principios que orientan el proceso penal y sin los cuales no se 
podría llevar a cabo el mismo a fin de establecer la garantía al derecho fundamental al debido proceso; todo esto ligado a la sana crítica del juez y los estándares de la prueba. Ahora bien. conforme al código de procedimiento penal (Ley 906, 2004) en su artículo $372^{\circ}$ sobre los fines de la practica probatoria, establece que "Las pruebas tienen por fin llevar al conocimiento del juez, más allá de duda razonable, los hechos y circunstancias materia del juicio y los de la responsabilidad penal del acusado, como autor o partícipe". Lo que indica que el juez penal debe estar convencido de que los hechos acusados son verídicos con una probabilidad de certeza aún mayor que cualquier otro tipo de audiencia; esto en la medida en que dentro de este proceso la apuesta es la libertad del procesado que, por un indicio probatorio débil, puede ser perjudicado como derecho humano, fundamental y constitucional. Queda ahora analizar los estándares probatorios, su relación con las garantías procesales en materia penal.

La definición de los estándares de la prueba, como puntos clave para el desarrollo de la práctica probatoria y la finalidad de la misma, es decir: que se tenga una certeza más allá de toda duda para el juez penal. La prueba es el medio por el cual se esclarecen los hechos y estos sólo pueden ser realizados con la medición de los estándares; respecto al cumplimiento de estos estándares, se subraya la posición de (Taruffo, 2005) al decir que:

"Los estándares de prueba que se consideran adecuados en los diferentes tipos de proceso constituyen el contexto en el que se coloca el esfuerzo probatorio de los conocimientos científicos. En línea general, estos conocimientos sirven como elemento para confirmar los enunciados sobre los hechos en función de su validez científica, y del grado de extensibilidad que les corresponde en el ámbito científico del que provienen" (p. 71).

Sumado a esto, es necesario recalcar que, el estándar probatorio penal de más allá de toda duda razonable, tiene un vínculo con el derecho fundamental de la presunción de inocencia, la cual identifica el principio de in dubio pro reo; esto, bajo las mismas consideraciones de la Corte Constitucional, en sentencia (T-827, 2005), identifica dos aspectos: (a) la forma en que opera la carga probatoria en manos del ente acusador, cuyo deber es demostrar la culpabilidad del procesado en caso de que exista; y (b) la imputación de la responsabilidad penal en la participación de los hechos delictivos a un individuo que no ha sido juzgado, por lo que entiende que no existe responsabilidad penal hasta que haya pasado y demostrado la culpabilidad en juicio. Bajo este concepto se entiende que el estándar de más allá de toda duda razonable, bajo la lupa de la sana crítica en el juez penal y la carga probatoria en el ente acusador, constituye garantías procesales. Sin embargo, queda ahora analizar, el impacto de la cuarta revolución industrial frente al derecho, más específico, su área procesal penal en materia de estándares probatorios y garantías procesales penales.

\section{La cuarta revolución industrial}

El fenómeno de la tecnología se ha convertido en la base de la sociedad contemporánea; ya el mismo crecimiento que esta ha presentado sirve como base fundamental del posible advenimiento que puede llegar a representar lo que (Schwab, 2013) ha denominado la cuarta revolución industrial. En efecto, al analizar minuciosamente con lupa las posibles consecuencias del prodigio de la tecnología dentro de las sociedades latinoamericanas, sus repercusiones llegarán a representar dentro de estas problemáticas, en muchos de los campos como los son: la economía, la 
política y las ciencias jurídicas. Sin duda alguna el acontecimiento es imparable y a las ciencias humanas no les queda otra opción que la adecuación vertiginosa para sostener el control social.

Si bien la primera revolución industrial se representa por la creación del ferrocarril en 1760; la segunda el nacimiento de la electricidad finalizando el siglo XIX; y, la tercera por el surgimiento del internet, la digitalización y el ordenador. La cuarta representa una autonomía notable por el crecimiento de la tecnología dentro de la vida humana, e incluso, una forma mejoramiento de algunos puntos de la misma, con el fin de facilitar la supervivencia del Hombre dentro del siglo XXI. Son tres los puntos de partida de (Schwab, 2013) para entender el funcionamiento de la tecnología de la Cuarta Revolución Industrial:

1. Dominios físicos: caracterizados por ser tangentes, se encuentra los puntos de innovación de los vehículos autónomos, la impresión 3D, la robótica avanzada y los nuevos materiales como el grafeno.

2. Dominio biológico: dentro de esta se observa la activación y/o modificación de genes; personalización del ADN; y, la reducción de enfermedades.

3. Dominio digital: establece la conexión más grande entre las aplicaciones, físicas y digitales, es decir, la relación entre servicios, productos y lugares con la gente, por medio de plataformas y aplicaciones; dentro de esta es notable el crecimiento del Blockchain. (pp. 18-25).

Cada una de estas nuevas tendencias marca de una forma innovadora el porvenir de la vida humana. Dentro del campo físico, en primer lugar, los vehículos autónomos, los cuales "representan unidades significativamente mejoradas, ya que permiten remplazar un chofer por la conducción autónoma al que le se ha agregado tecnología de alto nivel (Li, Díaz, Morantes, \& Dorati, 2018). Con esto se entiende que la misma tecnología desplaza al conductor (humano) por una serie de comandos organizados de forma algorítmica, información alimentada a través del Big Data que plataformas como Google permiten su crecimiento; esto en la medida en que el "universo digital de datos se dobla cada dos años y que el $70 \%$ de datos es creado por los mismos consumidores y el 20\% por empresas; así para el 2020 se predice

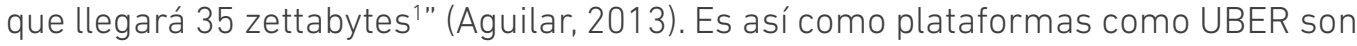
ejemplos de construcción de este tipo de tecnología; es menester destacar, como lo indica (Diez Ramírez, 2019) que "el 18 de marzo esta empresa deja las pruebas sobre vehículos autónomos tras la muerte de un peatón, producto de un choque con este tipo de vehículos" (p. 28).

Dentro del mundo físico de la Cuarta Revolución Industrial se observa que la creación de robótica avanzada ha ido implementando dos puntos básicos de la tecnología, por un lado, se encuentra la inteligencia artificial y por el otro el Big Data. Uno de los elementos más importantes es el segundo, pues, al igual que los vehículos autónomos, para la robótica avanzada se convierte en la fuente de información que permite el procesamiento de datos. Lejos de los paradigmas que han presentado los robots en la sociedad, estos han ido avanzando y adentrándose como utensilios en el campo del derecho, no como maquinas semihumanas, sino como equipos que permiten el análisis de información. Verbigracia Prometea: proyecto que en Argentina sirve para establecer resoluciones rápidas en materia judicial; mientras en Colombia el plan piloto de la 
Corte Constitucional la ha ejercido como medio de análisis ante la problemática de las tutelas que surgen a diario dentro la Alta Corte (GECTI, 2019). La robótica avanzada se representa por el surgimiento de la inteligencia artificial y se pone de utensilio dentro de los diversos campos de las ciencias exactas y sociales, al igual que las empresas.

Conjuntamente, cabe resaltar la creación de Ross, siendo el primer ordenador robótico que litiga a través de la inteligenciar artificial, actuando a través de un sistema operativo de inteligencia artificial conectado directamente con la base de datos de las cortes estadounidenses, lo cual le permite el procesamiento de información actualizada para así generar un silogismo a través de la adecuación del caso (Reategui, 2018).

Es notorio que el desarrollo de la inteligencia artificial dentro del derecho es un utensilio al servicio de la justicia; ahora bien, a través de este, verbigracia, el caso de Prometea y la Corte Constitucional, o, Ross, representan una forma de utilizar el almacenamiento masivo de datos para el desarrollo del derecho dentro de la Cuarta Revolución Industrial. Es menester entender que, conforme al principio del derecho y la sociedad como unísonos, la inteligencia artificial es la herramienta idónea que permite esa adecuación dentro del desarrollo procesal, pero esta funciona a través del Big Data, con lo cual sería obsoleto su propio crecimiento.

Sumado a la parte física de la Cuarta Revolución industrial se puede observar la impresión en 3D y los nuevos materiales, aspectos que denotan un impactante crecimiento a nivel industrial; el primero consiste en una impresión capa a capa hasta construir un modelo tridimensional, utilizable desde aerogeneradores hasta implantes médicos, lo que conlleva a una nueva forma de sostener la salud a través de la implantación de órganos; el segundo, son materiales ligeros, sólidos, reciclables y adaptables. (Schwab, 2013, págs. 20-21).

Además del impacto a nivel físico, como se ha observado, la nueva tecnología y el incremento que se da dentro del mundo digital avanza aceleradamente; la conexión que se genera de las cosas hacia el Internet o el llamado internet de las cosas. Es el crecimiento de sensores que conectan todo, siendo ampliamente accesible y permitiendo la expansión de los datos a cada instante. Un ejemplo de esta tendencia que permite un respectivo control sobre las cosas en tiempo real y sin distancia intermedia es el Blockchain, siendo una red permite establecer un control financiero sobre las transacciones antes de que la misma pueda ser registrada y aprobada; identificándose al mismo como un libro de contabilidad distribuido; si bien el impacto del mismo por el momento sólo es conocido a través del bitcoin, se espera que en el futuro exista un control símil en temáticas relacionadas con "certificados de nacimiento y defunción, títulos de propiedad, licencias de matrimonio, títulos académicos, reclamaciones de seguros, procedimientos médicos, votos electorales $y$, esencialmente, cualquier tipo de transacción que pueda ser expresada en forma de código" (Schwab, 2013).

A través de esto se evidencia que el campo de la digitalización convertirá el Big Data en el nuevo modelo de información, debido a su constante actualización generada por los usuarios y las empresas. En sí el internet de las cosas es un medio de digitalizar la parte física de la realidad para ser observada y procesada a través de un sistema algorítmico conforme a diversas finalidades dentro de la vida social. Es por ello que la parte digital llega a impactar de forma directa a cada individuo. Sumado a esto, el sentido digital de la Cuarta Revolución Industrial parece ser el camino recto 
por el cual se transita en este momento a través del internet y las redes sociales: el fundamento digital de la cuarta revolución industrial es la mayor innovación y la base de progreso de la misma. Las plataformas como UBER, FACEBOOK y ALIBABA son ejemplo de un nuevo modelo industrial formado a través de los datos, en los cuales, estas no crean o impulsan los mismos, sino que son intermedios entre los usuarios mismos que aumentan el almacenamiento masivo de datos. El impacto del Big Data por este tipo de aplicaciones y plataformas digitales permite conectar con las llamadas las tres $V$, en la medida en que en un sistema globalizado el volumen de información se acrecienta a cada minuto; la velocidad con respecto a su creación está en aumento cada año, duplicándose; y, la variedad toca desde los campos industriales, el entretenimiento y las transacciones financieras (Pruvost, 2015).

Por último, el impacto de la Cuarta Revolución Industrial en la biología es, como expresa (Schwab, 2013) sencillamente impresionante; la modificación del ADN tendrá un impacto en la medicina y la agricultura. Puntualmente, los problemas que se prevén conllevan a criterios en primer lugar morales con respecto a la modificación del ADN en las generaciones futuras y además de las modificaciones celulares que conllevan a una alteración en los tejidos humanos y las formas de superar las concernientes consecuencias de implementar células animales para ayudar a los compuestos humanos (xenotrasplante) o utilizar la impresión 3D para la creación de nuevos órganos (bioimpresión). El mundo jurídico debe estar atento a las posibles anomalías que estos procedimientos pueden llegar a desencadenar dentro de la vida social.

Así, la Cuarta Revolución Industrial, como se ha evidenciado, es un nuevo punto de partida ante el cual es necesario que las ciencias sociales comiencen a generar medios de coerción, los fundamentos físicos y digitales, al igual que los biológicos, conllevan a una apertura en un mundo donde las ciencias económicas encontrarán un modelo de mercado imparables; las ciencias políticas nuevos tipos de sociedades actualizadas con un nivel de compresión del mundo digital en crecimiento; las ciencias jurídicas un nuevo vacío legal que se expande milimétricamente. Dentro del crecimiento de la tecnología se observa la tensión entre el progreso y los valores, solidarios e individuales; además que, en el respectivo crecimiento de las innovaciones, la condición humana no está exenta a los respectivos cambios y por ende las comunidades; indica (Schwab, 2013) que:

"Las nuevas formas de medios digitales, que constituyen un componente esencial de la cuarta revolución industrial, impulsan cada vez más nuestra estructura individual y colectiva de sociedad y comunidad. Como el Foro analiza en su informe sobre medios digitales y sociedad (Digital Media and Society), conectan de una manera completamente nueva a las personas a escala tanto individual como colectiva, lo cual les permite a los usuarios mantener amistades a lo largo del tiempo y a distancia, crear nuevos grupos de interés y permitir que aquellos que están social o físicamente aislados se conecten con personas de ideas afines. La alta disponibilidad, los bajos costos y los aspectos geográficamente neutrales de los medios digitales también permiten una mayor interacción a través de las fronteras sociales, económicas, culturales, políticas, religiosas e ideológicas" (p. 76). 
Esta nueva revolución conlleva a entender los siguientes puntos: (a) es imparable el desarrollo de las nuevas tecnologías en la globalización; (b) el mundo de las innovaciones conlleva a una serie de nuevos problemas alternos, como es el caso de los vehículos autónomos, la robótica y la bioimpresión, donde se presenta un marco posible de afectación a los derechos individuales; (c) la red digital en su incremento aumenta el uso de almacenamiento masivo de datos y con ello se encuentra un nuevo mundo que representa constantemente vacíos legales y alternativas de desarrollo dentro del mundo jurídico a través del Big Data; (d) el mundo biológico va expandir las fronteras sobre el concepto de la vida entendido dentro de las legislaciones y por ende se convertirá en otro vacío legal; (e) ante el crecimiento de estos puntos, las sociedades que no están exentas al desarrollo, se irán adecuando a nuevos procesos digitales que se relacionan en su mayor medida al Blockchain; (f) el surgimiento de la sociedad digital conllevará a las ciencias políticas y jurídicas a moldear nuevas alternativas para establecer el control social. Cada sociedad será individualizada y se unirán únicamente a través de la red o el internet de las cosas.

Ante estas nuevas posiciones que representa la sociedad digital se debe generar un respectivo uso dentro de las ciencias sociales, no en búsqueda de la tecnificación total de las mismas, sino en un respectivo acercamiento a la digitalización como herramienta en el derecho, punto que se puede observar en conceptos como: prueba digital, búsqueda selectiva en base de datos, notificación electrónica, el uso de teleconferencia y video conferencia; (Pájaro Moreno, 2014), habla de las finalidades del uso de las nuevas tecnologías dentro del proceso, las cuales deben estar vinculadas con los principios de celeridad y economía procesal, en búsqueda de reducir el tiempo de actuación del aparato judicial; según el mismo, los problemas del proceso se evidencia en el tiempo que puede poseer el mismo por algunos trámites, desde los requisitos formales hasta los respectivos recursos, puntos que pueden ser automatizados por el uso de las nuevas tecnologías de la información y las comunicaciones (TIC); asimismo a través de las TIC se puede establecer la inmediatez dentro de las actuaciones que requieren del correo, como es el caso de las notificaciones; define Pájaro Moreno (2014) que las tecnologías de la información realizan una articulación del proceso con la realidad, que, como hemos visto hasta el momento, se hace cada vez más digital. Una vez definida la relación entre la cuarta revolución industrial y el derecho, corresponde analizar, a fin de delimitación, aquellos sistemas de IA que se han aplicado y entender la relación entre estos con las garantías procesales a fin de analizar su impacto con el estándar probatorio penal.

\section{Big Data e IA en el derecho probatorio}

A modo de silogismo se debe entender que: los avances que representa la Cuarta Revolución Industrial sobre la sociedad digital, el internet de las cosas y el almacenamiento masivo de datos y Big Data son los puntos más esenciales para generar una innovación sobre el aparato judicial en Colombia, fenómeno que se ha ido implementando a través del Plan de justicia digital y otros puntos que se podrán observar en el actual apartado. En primer orden, el manejo y el almacenamiento de datos son conceptos diferentes que se relacionan en el campo procesal; en primer orden, el tratamiento de datos, en el esquema procesal penal, debe poseer todas las garantías procesales a fin de no vulnerar los derechos del procesado y establecer la nulidad de la prueba por ser ilegal, es decir, tomada vulnerando derecho fundamentales; por otro lado, el almacenamiento masivo o Big Data, constituye las bases de datos que pueden existir, no sólo en las entidades públicas sino también las privadas, conforme a las capacidades analizadas en el acápite anterior. Es así como el Big Data conlleva a un análisis más profundo en su relación con los escenarios jurídicos. 
En primer orden y conforme al artículo $10^{\circ}$ de la ley 527 de 1999 que indica la relación entre los datos o mensajes de datos como medios probatorios admisibles, aspecto que genera la primera relación entre los almacenamientos masivos y la prueba. En el artículo $11^{\circ}$ de la ley 527 de 1999 se observa que "Para la valoración de la fuerza probatoria de los mensajes de datos a que se refiere esta ley, se tendrán en cuenta las reglas de la sana crítica y demás criterios reconocidos legalmente para la apreciación de las pruebas. Por consiguiente, habrán de tenerse en cuenta: la confiabilidad en la forma en la que se haya generado, archivado o comunicado el mensaje, la confiabilidad en la forma en que se haya conservado la integridad de la información, la forma en la que se identifique a su iniciador y cualquier otro factor pertinente". Bajo estos puntos se entiende que el Big Data, en cuanto constituye una fuente primaria de información, aspecto que, siguiendo las garantías procesales, permite un mayor desarrollo sobre los principios procesales de celeridad y economía con la finalidad de otorgar una mayor eficiencia dentro de la administración de justicia. A este punto se le puede sumar que la ley 527 de 1999, puntualiza los respectivo al mensaje de datos: "La información generada, enviada, recibida, almacenada o comunicada por medios electrónicos, ópticos o similares, como pudieran ser, entre otros, el Intercambio Electrónico de Datos (EDI), Internet, el correo electrónico, el telegrama, el télex o el telefax"; aspecto que se incrementa cada dos años conforme a los planteamientos preliminares de la Cuarta Revolución Industrial.

Asimismo, el aparato judicial en materia penal, establece un medio de inspección sobre los datos que se mencionan y este es la "búsqueda selectiva en base de datos" que establece el artículo $244^{\circ}$ del código de procedimiento penal que dicta que: "La policía judicial, en desarrollo de su actividad investigativa, podrá realizar las comparaciones de datos registradas en bases mecánicas, magnéticas u otras similares, siempre y cuando se trate del simple cotejo de informaciones de acceso público. Cuando se requiera adelantar búsqueda selectiva en las bases de datos, que implique el acceso a información confidencial, referida al indiciado o imputado o, inclusive a la obtención de datos derivados del análisis cruzado de las mismas, deberá mediar autorización previa del fiscal que dirija la investigación y (se aplicarán, en lo pertinente, las disposiciones relativas a los registros y allanamientos)"2. Con esto se abre una relación entre el Big Data y el estándar probatorio de más allá de toda duda razonable, pues permite, respetando el debido proceso y ante el juez de control de garantías, acceder a pruebas que permitan inferencias razonables en la búsqueda material de la verdad; así el tratamiento de esta información de índole personal constituye una base para la sana crítica del juez natural penal. Además, el estándar de más allá de toda duda razonable se encuentra sumergido el derecho constitucional de presunción de inocencia y el desarrollo del debido proceso del artículo $29^{\circ}$ de la Constitución Política de 1991. Ahora bien, la protección que la ley 1581 de 2012 realiza sobre los datos que regula la ley 527 de 1999 presupone la respectiva protección judicial y el apoyo condicionado de esta herramienta para el esclarecimiento factico, lo que integra el uso del Big Data para regular conductas típicas descritas dentro del tipo penal como lo son los delitos cibernéticos.

Sin embargo, por el principio procesal del análisis probatorio en conjunto, es menester que la búsqueda selectiva en base de datos solo puede generar una orientación por parte del juez de control de garantías, pues atribuirla como factor significativo más allá del que puede poseer dentro de la práctica probatoria, sería atentar contra el debido proceso. Asimismo, se debe entender que la racionalidad por parte del juez para tomar las pruebas en conjunto está bajo el efecto de la sana crítica y las demás

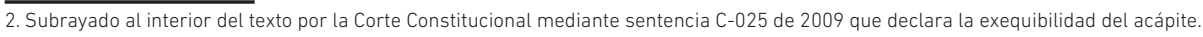


garantías procesales. Entendiendo que el acceso a estas cantidades de información puede conllevar a despejar las dudas en la absolución o condena del investigado, constituye, por ende, una herramienta útil para la sana crítica. A fortiori, se puede analizar el impacto de esta herramienta en el precedente judicial, aspecto de estricta obediencia para los jueces; el profundo análisis frente al impacto del precedente judicial el carácter vinculante de este mismo en las decisiones judiciales, en los cambios verticales y horizontales de la línea jurisprudencial, aspectos altamente estudiados por (López Medina, 2006), entienden la importancia de este para la sana crítica; constituyendo el Big Data jurisprudencial en una herramienta de estricta vinculación que obliga al juez a seguir la línea o alejarse de la misma con una explicación racional fundamentada para ello.

Por otro lado, si bien el precedente judicial entiende una vinculación directa y orienta la decisión del juez, la jurisprudencia entiende una cantidad exacerbada de decisiones judiciales que constituyen o no el mismo precedente judicial, la necesidad de procesar esta información a fin de continuar las líneas vinculantes es muy puntual: para esto está la necesidad de aplicar la IA, conforme a los planteamientos por parte de la Cuarta Revolución Industrial, es menester considerar los avances que se pueden representar a través de la Inteligencia Artificial, con modelos como Ross y Prometea que permiten una conexión entre el Big Data al servicio de la depuración de información a y través de un modelo algorítmico que se adecua al caso en concreto. Si bien la Corte Constitucional implementa el modelo de Prometea en un plan Piloto sobre el exceso de tutelas que se presentaron en materia de salud, con esto no se habla de una sustitución de modelo judicial adecuada en su totalidad sobre la sociedad digital, sino el manejo como herramientas para el juez dentro de sus decisiones, como en el caso del juez constitucional al decidir la viabilidad de la tutela sobre supuestos generales que tendrían el modelo de inteligencia artificial Prometea.

Aquí se recalca, que, en el 26 de mayo del 2019, Colombia acepta las directrices de la OCDE sobre el manejo de la inteligencia artificial, la cual describe los siguientes principios básicos para el manejo de la Inteligencia Artificial:

1. Crecimiento inclusivo, desarrollo sostenible y bienestar: donde las partes interesadas deben participar de forma proactiva en la administración responsable de la inteligencia artificial para lograr resultados beneficiosos para las personas y el planeta

2. Valores centrados en lo humano y equidad: por este los actores de la Inteligencia Artificial deben respetar el Estado de derecho, los derechos humanos y la democrático a lo largo del ciclo de la vida de la IA. Para este fin los actores de la IA deben implementar mecanismos salvaguardas como la capacidad de determinación humana

3. Transparencia y explicabilidad: los actores de la IA deben estar comprometidos con la divulgación con respecto a los sistemas de Inteligencia Artificial.

4. Robustez, seguridad y protección: los sistemas de seguridad de la IA deben ser robustos y seguros durante su ciclo de vida, con un uso previsible sin ser riesgoso. Para este fin los actores de la inteligencia artificial deben garantizar la trazabilidad en relación con los conjuntos de datos, procesos y decisiones tomadas. 
5. Responsabilidad: los actores de la IA deben ser responsables del buen funcionamiento de los sistemas de inteligencia artificial con respeto de los cinco principios en función de sus roles y contextos (Recomendation of the council on Artifical Intelligence, 2019).

Esta nueva implementación de la inteligencia artificial es un paso necesario para la adecuación de nuevos modelos similares a Prometa que permitan una respectiva celeridad y economía procesal; debido a que la inteligencia artificial se sostiene por el uso del Big Data, la fusión de estos dos admitiría el manejo idóneo de las plataformas dentro de lo estipulado por la ley 527 de 1999 sin llegar a vulnerar los derechos individuales protegidos por la ley 1581 de 2012. Así, los estándares de la prueba como probabilidad de verdad y más allá de toda duda razonable pueden permitir un manejo científico con mayor claridad y mejor claridad en la prueba para remitir decisiones judiciales más transparentes.

En materia probatoria, se observa aspectos como la prueba, los medios probatorios, las garantías procesales, la sana crítica y la aplicación del precedente judicial (aspecto unido al Big Data jurisprudencial); si bien la implementación de las nuevas tecnologías al derecho se han ido puntualizando como herramientas, estas no pueden constituir un remplazo a los criterios valorativos del juez en la sana crítica; constituye así que, el estándar probatorio de más allá de toda duda razonable, entiende la aplicación de dos herramientas puntuales: la IA y el Big data Jurisprudencial, a fin de alimentar las bases científicas de la sana crítica generando una delimitación de la información jurisprudencial y aplicando el precedente vinculante; ahora bien, la inteligencia artificial también constituye una base algorítmica de análisis del material probatorio en lo pertinente a la valoración probatoria; (Nieva Fenoll, 2018), analiza esta situación frente a las pruebas.

En primer orden, su análisis se centra en la declaración de personas, analizando el factor de la memoria humana y su deficiencia como punto de partida, entiende el mismos que para realizar un estudio de tallado de los aspectos más importantes en las declaraciones personales, en lo entendido de la psicología del testimonio, en la valoración de las circunstancias, programas como ADVOKATE, que toma aspectos como la distancia del observador, su visibilidad, el conocimiento previo entre el testigo y la persona observada, el lapso de observación, la competencia de edad y capacidad mental, errores de descripción, para establecer la credibilidad testimonial en un proceso; con lo que, indica el jurista: "estos programas sustituirán con seguridad la «experiencia» de los jueces en la valoración de la credibilidad de una persona de acuerdo con los factores situacionales" (p. 83).

Respecto a los parámetros de evaluación de la declaración probatoria, indica Nieva Fenoll (2018), este mismo sistema de IA, puede ayudar a la valoración probatoria en lo respectivo a las declaraciones testimoniales en cuatro puntos que resalta el autor: (a) la coherencia de la declaración (libre de contradicciones); (b) la capacidad del interrogado de recuperar el escenario donde sucedieron los hechos (contextualización); (c) la corroboración de otros medios probatorios declarados; y (d), la existencia de comentarios oportunistas sobre lo que no ha sido objeto de la declaración. Aspectos que pueden ser incluidos dentro de un algoritmo y pueden facilitar el análisis probatorio. Conjuntamente el autor analiza en que escenarios puede verse la IA en medio de la prueba documental, más allá de la simple lectura del documento y observando aspectos mínimos que pueden determinar la decisión judicial, esto en 
aspectos relacionados con quien emite el documento y la calidad del mismo; expone lo siguiente Nieve Fenoll (2018):

El uso de un vocabulario familiar en un documento negocial podría estar desvelando una estafa o algún vicio del consentimiento. La riqueza léxica de una carta podría revelar que su autor no pudo ser una persona de un nivel cultural bajo, por lo que podría descubrirse la falsedad de la autoría del documento. En la averiguación de dicha autoría también podrían contrastarse otros documentos indubitados del supuesto autor con el que queremos analizar. Todos usamos expresiones y maneras de redactar que obedecen a nuestras costumbres habituales, de manera que, si en una lectura humana de esos documentos pueden detectarse esas similitudes, una herramienta de inteligencia artificial podría hacer cálculos estadísticos sobre las mismas, lo que mejoraría la calidad de las conclusiones al respecto (p. 92).

Entendiendo que este tipo de aplicación tecnológica sólo puede constituir una guía y la valoración final está en el juez, por ende, en el factor humano. Por último, el autor recalca la prueba pericial y su relación con la IA, entendiendo la lejanía entre la ciencia jurídica y aquella que es evaluada por el perito, aspecto en el cual la Inteligencia Artificial puede ser de auxilia al ente juzgador en (a) la valoración y credibilidad del perito; (b) los criterios Daubert. En el primer punto, tiene una problemática mayor, pues los criterios de evaluación frente al Curriculum por parte de la IA solo pueden ser consideraciones cuantitativas y no cualitativas, aspectos que no logra orientar la calidad del perito. Es necesario recalcar, en el segundo plano, que los componentes de los criterios Daubert son:

1. Que la técnica haya sido elaborada siguiendo el método científico, en el sentido de que haya sido verificada empíricamente con intentos de falsificación y refutación.

2. Que la técnica empleada haya sido objeto de revisión por parte de otros expertos y haya sido publicada.

3. Indicación del grado de error de la técnica.

4. Existencia del mantenimiento de estándares y controles sobre la fiabilidad de la técnica.

5. Consenso en la comunidad científica sobre la técnica empleada (estándar Frye) (Nieva Fenoll, 2018, págs. 96-97).

El segundo punto está en la valoración de estos criterios por parte de la IA como medio de ayuda para el juez. Dado que los criterios Daubert tienen una estructura algorítmica estos, contrario al punto (a) no son cualitativos frente al perito sino frente al método utilizado por este. Sin embargo, dado que la finalidad probatoria es la orientación al juez, el valor que puede dar la IA frente a este tipo de prueba es muy escaso y solo constituye une herramienta débil por constituir análisis más puntuales como en el caso de otro tipo de pruebas (documentales) frente a la estricta legalidad o idoneidad del material probatorio]; se entiende, abajo estos preceptos que la IA solo puede poseer una estricta relación con datos masivos procesados que den una orientación no definitiva al ente juzgador. A fin de que, como indica Nieve Fenoll (2018): "que una persona entre en una serie de parámetros de riesgo no quiere decir que haya cometido un delito en concreto. Puede que la persona habite en un barrio 
determinado, sea de una raza concreta, tenga antecedentes o posea un determinado nivel de estudios. Nada de ello importa a la hora de juzgar, puesto que en el momento de establecer su culpabilidad o inocencia solo se deberán tener en cuenta las pruebas que le relacionen con los hechos concretos de aquel proceso 6, y nada más. No factores de riesgo que hagan de él un potencial criminal, pero a quien no se pueda relacionar con los hechos. Ya es un error sentenciar así actualmente, y se observa con cierta frecuencia en los casos de insuficiencia probatoria, en los que se buscan a veces dictámenes psicológicos que hagan de la personalidad del reo el indicio fundamental de la comisión del delito. De hecho, obrar de ese modo tiene, por desgracia, gran aceptación social. Pero es completamente rechazable por las razones apuntadas" (p. 101). Estos factores serian una directa violación a las garantías procesales.

\section{Conclusión}

El problema planteado relacionada cuatro componentes principales: (a) las garantías y derechos procesales en materia penal; (b) el impacto de la cuarta revolución industrial en el mundo jurídico y los componentes que se relacionaban con los escenarios probatorios, siendo estos con mayor énfasis la Inteligencia artificial (IA) y el almacenamiento masivo de datos (Big Data); (c) la relación entre las garantías procesales del procesado en materia penal y el estándar probatorio de más allá de toda duda razonable como límite de estricta aplicación frente al juez penal; y (d) la IA y el Big Data como herramientas en el derecho probatorio y el impacto de estos frente al estándar probatorio-penal. La relación de estas variables nos conllevo al análisis del uso de las herramientas de la cuarta revolución industrial (IA \& Big Data) a fin de establecer mejoras o desmejoras a la aplicación del estándar de la pruebe penal a fin de constituir garantías procesales al procesado y, por ende, establecer el respeto de sus derechos constitucionales reconocidos.

En primer orden se definió las garantías procesales, siendo estas: el acceso a la administración de justicia, derechos procesales, recursos, segunda instancia y decisiones motivadas; juez natural, defensa técnica, audiencia pública, independencia del juez e imparcialidad; todo esto encaminado a la garantía del derecho fundamental del debido proceso, reconocido en la Constitución Política y en los principios de la ley procesal penal. Posteriormente se relacionó el debido proceso a la prueba, definiendo los alcances y límites de la prueba en el proceso penal y entendiendo que esta es la base de orientación de la decisión judicial, definiendo factores que determinan la prueba como: su concepto, el órgano y el sujeto, su teleología, la fuente de la misma, su objeto, su procedimiento, los medios probatorios, la carga de la prueba en cabeza del ente acusador y la valoración de la prueba que tiene una estrecha relación con la sana crítica del juez, la cual, a su vez, está compuesta por la lógica, la experiencia, la equidad y las ciencias. Aunado a esto se entendió el precedente judicial como factor clave, por su criterio de vinculación imperativa a las decisiones judiciales.

Posteriormente se analizó el impacto de la Cuarta revolución industrial, considerando sus tres dominios: (a) físico con la innovación de los vehículos autónomos, la impresión 3D, la robótica avanzada y el grafeno; (b) biológico: activación y /o modificación de genes, personalización del ADN, reducción de enfermedades; y (c), digital: apps físicas y digitales, plataformas, Blockchain, Big Data e Inteligencia Artificial. Cada uno con su respectivo impacto jurídico o vacío legal para ser moldeado. De estos avances se extrajeron dos componentes que se han visto en la aplicación del mundo jurídico: el Big Data y la IA, esto en modelos como Ross o Prometea, que habían sido utilizados como herramientas en el mundo jurídico. De esta se entendió 
la estrecha relación del Big Data con la jurisprudencia, pues esta cumplía con los requisitos de la misma (almacenamiento masivo de datos que representaban las sentencias y su incremento constante), en lo que se determinó como Big Data Jurisprudencial y entendía una necesidad de procesamiento a fin de afianzar la sana crítica con precedente judicial vinculante. Aspecto que necesita de un procesamiento de información a través de la IA.

Finalmente se analizó el impacto de la IA y el Big Data en el derecho probatorio, entendiendo definiciones legales frente a I uso de datos como prueba y entre estos las definiciones de la ley 527 de 1999 respectivo a la valoración probatoria de los mensajes. Destacando, igualmente, escenarios probatorios como la "búsqueda selectiva en base de datos" ante el juez de control de garantías, respetando los derechos y garantías procesales. Esto a fin de analizar la valoración de la prueba y su relación con la IA. Se tomaron las pruebas testimoniales, documentales y periciales. Frente al primero se tomaron en cuenta los factores de la psicología testimonial, en lo pertinente a la declaración de personas y las problemáticas de la memoria en la valoración de las circunstancias en programas como ADVOKATE, que puede llegar a desestimar contradicciones, contextualizaciones, declaraciones probatorias que no se han incluido y comentarios oportunistas. A fin de orientar la decisión del juez. En la prueba documental, la IA puede constituir a analizar sus componentes en tanto quien emite el documento, la forma del documento y la calidad del mismo, aspecto que deben sostener una congruencia sino demostraría su falsedad. Por último, en la prueba pericial no puede existir la misma eficiencia con la IA, pues los valores emitidos por esta no están centrados en la calidad del perito sino en la cantidad, aspecto que no puede conllevar a desacreditar al mismo. Sin embargo, en lo entendido de los criterios Daubert, por su estructura algorítmica, puede servir de orientación frente al método que realizo el perito. Por ende, estos factores sirven como una herramienta para el juez.

Esto entiende que se pueden sostener las garantías procesales del procesado y establecer una cercanía probatoria acorde al estándar más allá de toda duda razonable a través de las herramientas de IA y Big Data que apoyan al juez y refuerzan la sana crítica a fin de emitir sentencia condenatoria o absolutoria. Estas herramientas son criterios de refuerzo cuantitativo en el valor de la prueba, pero no puede existir un total desligamiento del factor humano que se representa en el juez a fin de que las valoraciones cuantitativas no determinan por si sola la culpabilidad o inocencia y asumir estos puntos por valoraciones numéricas conllevaría a violaciones a las garantías procesales y por ende vulneraria el derecho al debido proceso. 


\section{Bibliografía}

Barrios González, B. (2003). Teoría de la sana crítica. Opínion juridica, 99-132.

Bobbio, N., \& Bovero, M. (1985). Teorías y fundamentos del poder político. Madrid: Grijalbo.

C-341, Ref.: Expediente D-9945 (Corte Constitucional 04 de junio de 2014).

Constitución Política. (1991). Procuraduría General de la Nación. Obtenido de Procuraduría General de la Nación: https://www.procuraduria.gov.co/guiamp/media/ file/Macroproceso\%20Disciplinario/Constitucion Politica de Colombia.htm

Diez Ramírez, a. (2019). Conducción autónoma: estado del arte, impacto sobre la movilidad y desarrollo del simulador de tráfico. Madrird: Universidad Politécnica de Madrid.

Ferrajoli, L. (1995). Derecho y razón: teoría del garantismo penal. Madrid: Trotta.

García Flores, F. (2002). Los elementos de la prueba. En I. C. procesal, La prueba (homenaje al maestro Hernando Devis Echandía (págs. 707-727). Bogotá: Universidad Libre de Colombia.

GECTI. (2019). memorias del evento Herramientas digitales al servicio de la justicia en Colombia: el caso prometea. Bogotá: Universidad de los Andes.

Joyanes Aguilar, L. (2013). Big Data ánalisis de grandes volumenes de datos en organizaciones. Mexico DF : Alfaomega.

Ley 1564, Diario Oficial No. 48.489 (Congreso de la República 12 de julio de 2012).

Ley 527, Diario Oficial No. 43.673 (Congreso de la República 21 de agosto de 1999).

Ley 906, Diario Oficial No. 45.658 (Congreso de la República 01 de septiembre de 2004).

Ley 906, Diario Oficial No. 45658 (Congreso de la República 01 de septiembre de 2004).

Li, Y., Díaz, M., Morantes, S., \& Dorati, Y. (2018). Vehículos autónomos: Innovación en la logística urbana. RIC, 34-39.

López Medina, D. (2006). El derecho de los jueces. Bogotá : Legis.

Nieva Fenoll, J. (2018). La inteligencia artificial y el proceso judicial. Madrid: Ediciones jurídicas y sociales S.A.

Pájaro Moreno, N. (2014). Nuevas tecnologías al servicio del proceso. Nuevas tecnologías al servicio del proceso. Cartagena: XXXV Congreso Colombiano de Derecho Procesal.

Pruvost, A. G. (2015). Segmentando el Big Data con Facebook. Simposio Argentino sobre Tecnología y Sociedad, 306-315. 
Reategui, F. C. (05 de septiembrer de 2018). Legis.pe. Recuperado el 15 de MARZO de 2019, de Legis.pe: https://legis.pe/ross-primer-abogado-robot-litiga-usando-inteligencia-artificial/

Recomendation of the council on Artifical Intelligence, OCDE legal instruments (Secretary-General of the OCDE 26 de mayo de 2019).

Schwab, K. (2013). La cuarta revolución industrial. Madrid: Debate.

T-827, Referencia: expediente T-1094239 (Corte Constitucional 10 de agosto de 2005).

Taruffo, M. (2005). Conocimiento cientídico y estándares de la prueba judicial. Justicia electoral, 59-72.

Taruffo, M. (2009). La prueba, artículos y conferencias. Mexico DF: Metropolitana. 